\title{
Gelatinases in Boar Seminal Plasma and Their Relation to Semen Indicators
}

\author{
Maja Zakošek Pipan, Marjan Kosec, Janko Mrkun, Petra Zrimšek \\ Clinic for Reproduction and Horses, Veterinary Faculty, University of Ljubljana, Slovenia \\ Received October 20, 2009 \\ Accepted May 13, 2010
}

\begin{abstract}
Matrix metalloproteinases were detected in reproductive tissues and seminal plasma of various animal species. The aim of this study was to determine for the first time the presence of gelatinases and metalloproteases in boar seminal plasma and to correlate the results with semen indicators. Gelatin zymography was used for simultaneous identification and measurement of gelatinase enzyme activity associated with their molecular weights.

Several gelatinase forms were identified in seminal plasma of boars. Those that were stimulated by $\mathrm{CaCl}_{2}$ and inhibited by EDTA and phenanthroline were considered as metalloproteases. Negative correlation between semen indicators (sperm index, sperm concentration and concentration of progressive motile sperm) and the concentrations of metalloprotease at $78 \mathrm{kDa}$ and $66 \mathrm{kDa}$ means that higher values of semen indicators correlate with lower concentrations of these metaloproteases in seminal plasma. Gelatinases with molecular weight of 225, 78 and $66 \mathrm{kDa}$ correlated with higher levels of acrosome damage. Samples with sperm index above $110 \mathrm{M} / \mathrm{ml}$ contained gelatinases of significantly lower band intensities at 78 and $66 \mathrm{kDa}$ compared to samples with SI less than $110 \mathrm{M} / \mathrm{ml}$. Bands with 225, 78 and $66 \mathrm{kDa}$ are suggested to belong to a dimer of MMP-9, proMMP-2 and mature MMP-2.
\end{abstract}

Matrix metalloproteinases, boar semen evaluation, semen characteristics

Numerous proteolytic enzymes and their inhibitors are localized in both spermatozoa and seminal plasma in the mammalian semen. The spermatozoa are rich in different proteases, which are mainly localized within the acrosomal vesicle (Tulsiani et al. 1998). Seminal plasma contains many proteinases originating either from testicular cells or prostate and other accessory sex glands. Most proteinases described for seminal plasma are serine proteinases, however, proteinases from other classes are present in semen from human and domestic mammals (Metayer et al. 2002).

The fertilization process requires breakdown of the physiological barrier during sperm penetration through the zona pellucida and the egg plasma membrane, but a detailed molecular mechanism is still unclear. It is suggested that matrix metalloproteinases (MMPs) can be involved in this process (Buchman-Shaked et al. 2002). The MMPs are a family of proteolytic enzymes capable of degrading specific components of extracellular matrix (ECM) at physiological $\mathrm{pH}$ in a zinc-dependent manner. MMPs and their tissue inhibitors (TIMPs) play a key role in many physiological processes, including ovulation and implantation. Although little is known about MMP expression and their exact function in the male reproductive tract, they are believed to be involved in the regulation of spermatozoal function (Hulboy et al. 1997).

Matrix-metalloproteinases (MMPs) are zinc-dependent proteinases involved in tissue remodelling, cell migration, and cell-cell interaction (Robinson et al. 2001), and are known as the main enzymes digesting the extracellular matrix. MMPs are secreted in inactive forms that are activated by cleavage of the inhibitory pro-peptide of about $10 \mathrm{kDa}$ (Nagase and Woessner 1999). Keeping sperm proteases in an inactive form is critical for maintaining cell integrity in order to ensure reproductive function of sperm cells (Zheng et al. 1994). A complex mechanism controlling MMP activation includes regulation at the level of gene expression, cleavage of inactive forms and inhibition of active MMPs

Address for correspondence:

Petra Zrimšek

Clinic for Reproduction and Horses

Veterinary Faculty, University of Ljubljana

Gerbičeva 60, Ljubljana, Slovenia
Phone: +38614779271

Fax: +38612832243

E-mail: petra.zrimsek@vf.uni-lj.si

http://www.vfu.cz/acta-vet/actavet.htm 
by endogenous inhibitors, primarily tissue inhibitors of MMPs (Nagase and Woessner 1999).

Gelatinases have been detected in epididymal fluids of ram, stallion and boar (Metayer et al. 2002). Metalloproteases, serine proteinases and serine proteinase inhibitors have been detected in turkey seminal plasma (Kotlow ska et al. 2005). Complexes of gelatinases and TIMP-1 and TIMP-2 (Shimokawa et al. 2003) or MMP-2 and MMP-9 (Shimokawa et al. 2002) were found in human seminal plasma. The first report of gelatinase in human sperms indicated higher 28-kDa gelatinase activity and lower 92-kDa MMP activity in normal compared to abnormal semen (Buchman-Shaked et al. 2002). TIMP-2 in bovine seminal plasma has been described as a factor influencing the bull fertility (McCauley et al. 2001). The role of TIMPs for human sperm function is most probably based on interaction with MMPs in spermatozoa (Baumgart et al. 2002). MMP-2 and MMP-9 were evaluated in human seminal plasma, where latent forms of both MMPs predominate, and pro-MMP-9 was detected in samples of low sperm concentration (Tentes et al. 2007).

The aim of this study was to examine the presence of gelatinases and metalloproteases in boar seminal plasma.

\section{Materials and Methods}

Semen samples and their analysis

Twenty-one semen samples were obtained from 12 to 24-month-old boars of various breeds. While the boar mounted a dummy sow, semen was collected with gloved hand using a clean semen collecting flask that filters gel, dust and bristles out. Semen was kept at the room temperature and analysed within $1 \mathrm{~h}$. Computer-assisted semen analysis (Hamilton Thorne IVOS 10.2; Hamilton Thorne Research, MA, USA) was performed with a Makler counting chamber (Sefi Medical Instruments, Israel) to determine sperm concentration and motility characteristics. Sperm morphology was examined in Giemsa-stained samples (Hafez 1993). Metabolic activity of spermatozoa was assayed using a spectrophotometric application of the resazurin reduction assay (Zrimšek et al. 2004; Zrimšek et al. 2006). Sperm index was calculated by multiplying the total sperm concentration by the square root of its motility multiplied by the percentage of normal sperm (Mahmoud et al. 1994).

Seminal plasma preparation

Samples of seminal plasma were prepared at the same time as evaluation of the semen. Following centrifugation at $818 \mathrm{~g}$ for $10 \mathrm{~min}$ at room temperature, the supernatant was further centrifuged at $13,000 \mathrm{~g}$ for $15 \mathrm{~min}$ at $4^{\circ} \mathrm{C}$ to separate seminal plasma, which was then aliquoted and frozen at $-80{ }^{\circ} \mathrm{C}$ until assayed.

Gelatin zymography

Gelatin zymography was performed on seminal plasma using a modified method of Laemmli (1970). The $7.5 \%$ separating polyacrylamide gel $(0.75 \mathrm{~mm}$ thickness) contained $0.12 \%$ pig skin type I gelatin (Sigma, Germany), whereas the 4\% stacking gel contained no gelatin. The samples of seminal plasma, diluted 1:5 in PBS, were denatured with SDS but not reduced. The mixture of molecular weight markers was diluted 1:4 with SDS reducing buffer and heated in a boiling water-bath for 5 min prior to loading on the gel. MMP-2 from human fibroblasts (Sigma) and MMP-9 from human fibroblasts (Sigma) were used as controls. Each sample of $10 \mu \mathrm{l}$ was loaded into a well and samples were electrophoresed at a constant $200 \mathrm{~V}$ for $45 \mathrm{~min}$. After electrophoresis, the proteins were allowed to renature by removing SDS by washing the gel in $2.5 \%$ Triton X-100 with gentle shaking for $30 \mathrm{~min}$ at room temperature. Gels were incubated overnight at $37^{\circ} \mathrm{C}$ in a reactivation buffer of $\mathrm{pH}$ 7.6 containing $50 \mathrm{mM}$ Tris/ $\mathrm{HCl}, 10 \mathrm{mM} \mathrm{CaCl}, 150 \mathrm{mM} \mathrm{NaCl}$ and $0.2 \%$ Brij 35. Following incubation, the gels were stained for 20 min with $0.1 \%$ Coomassie brilliant blue R-250 (Bio-Rad, Germany) in a solvent mixture containing $40 \%$ methanol and $10 \%$ acetic acid. After staining, the gels were de-stained in the same solution in the absence of dye until gelatinolytic bands became white against a blue background. De-stained gels were scanned using a Model GS-700 Imaging Densitometer (Bio-Rad). Relative intensities of gelatinolytic bands, representing the gelatinolytic activity, were quantified using GIMP 2.2.10 software. Average pixel intensities of the bands were reduced for the pixel intensity of the gel's background.

To examine the inhibition of enzyme activity, gels were also incubated in reactivation buffer without $\mathrm{CaCl}_{2}$, and reactivation buffer containing $10 \mathrm{mM}$ EDTA or $2 \mathrm{mM}$ o-phenanthroline.

\section{Statistical analysis}

Spearman rank correlation coefficients were calculated to correlate the concentrations of gelatinases with each other and with sperm indicators such as sperm concentration, motile sperm concentration, sperm index, metabolic activity, $\%$ of morphological normal spermatozoa and $\%$ of spermatozoa with damaged acrosome.

In order to investigate the possible association of gelatinases with the above sperm indicators, semen samples were divided into two groups according to a sperm index $(\mathrm{SI})$ of $110 \mathrm{M} / \mathrm{ml}$ : group $\mathrm{A}(\mathrm{SI} \leq 110 \mathrm{M} / \mathrm{ml} ; \mathrm{n}=9)$ and 
group B (SI > $110 \mathrm{M} / \mathrm{ml} ; \mathrm{n}=12)$. A sperm index was calculated by multiplying sperm concentration by the square root SQRT of percentage sperm motility multiplied by morphology ( $\%$ normal forms) using the lowest values of normal range of semen parameters (Hafez 1993).

The statistical analysis included descriptive statistics for the above indicators. Comparison between the groups of semen samples was performed with Mann-Whitney U test using SigmaStat 3.5 (SYSTAT Software Inc.) software.

\section{Results}

Boar seminal plasma contains several proteinase activities that are capable of hydrolysing gelatine. Bands of gelatinolytic activity were observed in a gelatin polyacrylamide gel with $\mathrm{Mr}$ values of $30,32,34,40$, and $45 \mathrm{kDa}$, a double band at $59 \mathrm{kDa}$ and bands at 64 , 66,78 and $225 \mathrm{kDa}$ (Fig.1, lane D). Gelatinase forms that were stimulated by $\mathrm{CaCl}_{2}$ and inhibited by EDTA and phenanthroline were considered as metalloproteases. The presence of $\mathrm{Ca}^{2+}$ was required for gelatinases with a molecular weight from 59 to $225 \mathrm{kDa}-$ if $\mathrm{CaCl}_{2}$ was omitted from the reactivation buffer, these activities were not observed (Plate IV, Fig.1, lane A). EDTA inhibited gelatinases with the molecular weight higher than $45 \mathrm{kDa}$ (Fig. 1, lane B), whereas phenanthroline inhibited all detected gelatinases (Fig. 1, lane C).

Table 1. Summary of spermatoanalytical and enzymatic examination

\begin{tabular}{|c|c|c|c|c|}
\hline & Mean & SD & Min & Max \\
\hline \multicolumn{5}{|l|}{ Spermatoanalytical examination } \\
\hline Sperm concentration $(\mathrm{M} / \mathrm{ml})$ & 176.67 & 56.03 & 62.83 & 254.33 \\
\hline Progressive motile sperm conc. $(\mathrm{M} / \mathrm{ml})$ & 84.26 & 34.95 & 18.85 & 136.13 \\
\hline Sperm index & 105.88 & 40.72 & 27.32 & 165.02 \\
\hline Normal morphology (\%) & 74.42 & 5.70 & 63.00 & 83.67 \\
\hline Acrosome damage $(\%)$ & 6.84 & 3.05 & 1.00 & 11.00 \\
\hline Resazurin reduction assay $\left(\mathrm{A}_{610}\right)$ & 0.0875 & 0.0418 & 0.0310 & 0.1510 \\
\hline \multicolumn{5}{|l|}{ Enzymological examination } \\
\hline $64 \mathrm{kDa}$ (pixels) & 128.10 & 41.62 & 30.33 & 187.67 \\
\hline $66 \mathrm{kDa}$ (pixels) & 111.38 & 53.18 & 1.00 & 174.67 \\
\hline $78 \mathrm{kDa}$ (pixels) & 27.90 & 15.91 & 1.00 & 57.00 \\
\hline $225 \mathrm{kDa}$ (pixels) & 16.48 & 9.87 & 5.83 & 53.67 \\
\hline
\end{tabular}

Spermatoanalytical and enzymatic examinations are summarized in Table 1. Band intensities at 78, 66 and $64 \mathrm{kDa}$ representing gelatinolytic activity correlate with each other significantly $(P<0.05)$. These metalloproteases also strongly correlated with the percentage of acrosome damage $(P<0.05)$. Activity of $66 \mathrm{kDa}$ also correlated significantly with metabolic activity (resazurin reduction assay). Gelatinolytic activity of $225 \mathrm{kDa}$ correlated only with \% acrosome damage. There was a negative correlation between the intensities of 78 and $66 \mathrm{kDa}$ bands and sperm concentration, progressive motile sperm concentration and sperm index (Table 2).

Both bands at 78 and $66 \mathrm{kDa}$ were negatively related to sperm index, sperm concentration and concentration of progressive motile sperm $(P<0.07)$. Other gelatinases with $\mathrm{Mr}$ between 32 and $45 \mathrm{kDa}$ correlated with each other $(P$ between 0.008 and $<0.001)$. Gelatinase at $59 \mathrm{kDa}$ correlated only with gelatinase at $45 \mathrm{kDa}(P=0.05)$. No correlation was observed between sperm characteristics and activity of gelatinases with $\mathrm{Mr}$ below $59 \mathrm{kDa}(P>0.05)$.

Significant differences in band intensity of metalloprotease at $66 \mathrm{kDa}$ and metalloprotease at $78 \mathrm{kDa}$ (Fig. 2) were observed between the groups with sperm index below and above $110 \mathrm{M} / \mathrm{ml}(P<0.05)$. Furthermore, these groups differed significantly in terms of 
Table 2. Spearman rank correlations between semen characteristics and metalloprotease levels

\begin{tabular}{|c|c|c|c|c|}
\hline \multirow{2}{*}{ Sperm characteristic and gelatinase } & \multicolumn{4}{|c|}{ Gelatinase (metalloprotease) $\mathrm{Mr}$} \\
\hline & $64 \mathrm{kDa}$ & $66 \mathrm{kDa}$ & $78 \mathrm{kDa}$ & $225 \mathrm{kDa}$ \\
\hline Sperm concentration & $-0.318(0.157)$ & $-0.563(0.0079)$ & $-0.418(0.0583)$ & $-0.043(0.850)$ \\
\hline Progressive motile sperm conc. & $-0.179(0.431)$ & $-0.485(0.0259)$ & $-0.405(0.0673)$ & $-0.070(0.758)$ \\
\hline SI & $-0.203(0.370)$ & $-0.521(0.0156)$ & $-0.422(0.0439)$ & $-0.080(0.724)$ \\
\hline Normal morphology $(\%)$ & $-0.146(0.520)$ & $-0.338(0.132)$ & $-0.442(0.0558)$ & $-0.043(0.850)$ \\
\hline Acrosome damage (\%) & $0.441(0.0452)$ & $0.759(<0.001)$ & $0.747(<0.001)$ & $0.498(0.0214)$ \\
\hline Resazurin reduction assay $\left(\mathrm{A}_{610}\right)$ & $0.228(0.314)$ & $0.455(0.0375)$ & $0.355(0.111)$ & $0.009(0.694)$ \\
\hline $66 \mathrm{kDa}$ & $0.800(<0.001)$ & & $0.777(<0.001)$ & $0.236(0.297)$ \\
\hline $78 \mathrm{kDa}$ & $0.604(0.0038)$ & $0.777(<0.001)$ & & $0.358(0.109)$ \\
\hline $225 \mathrm{kDa}$ & $0.0914(0.690)$ & $0.236(0.297)$ & $0.358(0.109)$ & \\
\hline
\end{tabular}

Statistical significance $(P)$ is shown in brackets. $P<0.1$ are bolded. $P<0.05$ was set as significant

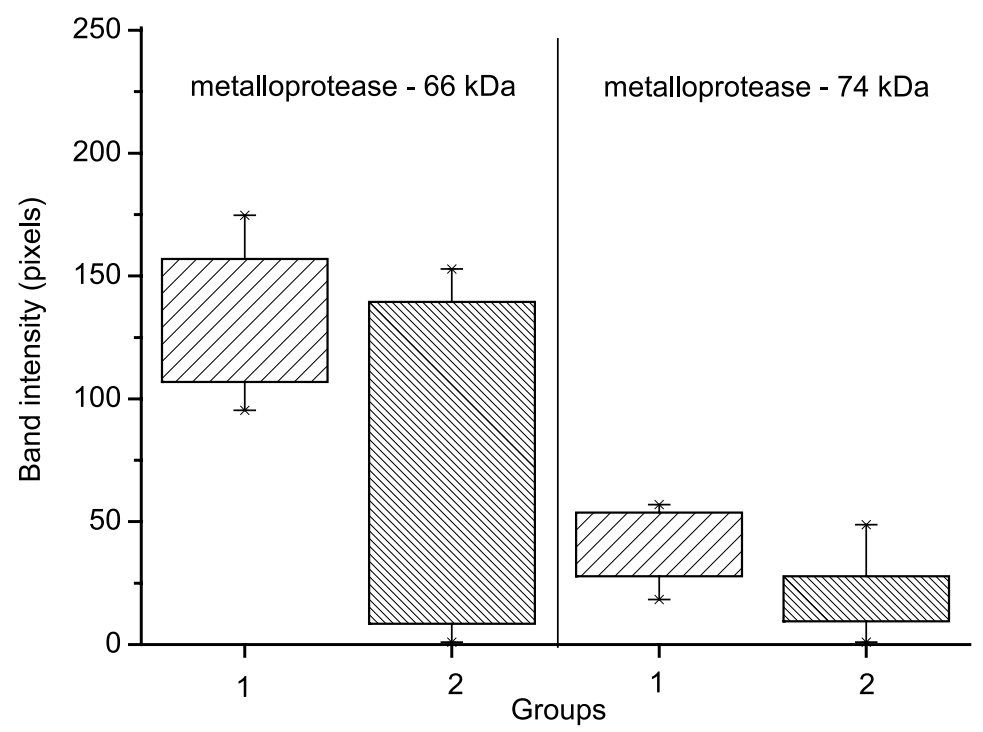

Fig. 2. Band intensity for metalloprotease of $66 \mathrm{kDa}$ and $78 \mathrm{kDa}$ in groups with different sperm indices

sperm concentration, concentration of progressive motile sperm, and metabolic activity $(P<0.001)$, morphology and percentage of acrosome damage $(P<0.005)$.

\section{Discussion}

Although gelatinases have been detected in boar epididymal fluids (Metayer et al. 2002), this is the first report of gelatinases in boar seminal plasma and their correlation with semen indicators. The influence of boar breed and age was not the aim of this study. Seasonal effect that could influence the electrophoretic profile of the zymograms was also not a part of this study; all samples were collected in spring.

Using gelatin zymography, we detected several gelatinases in boar semen. The method used can also detect the inactive proforms of gelatinase because SDS causes activation of the enzymes without proteolytic cleavage of the inhibitory N-terminal sequence (BirkedalHansen and Taylor 1982). 
All gelatinases with molecular weights higher than $45 \mathrm{kDa}$ were metalloproteases, based on inhibition of their enzyme activities by the metalloprotease inhibitors EDTA and phenanthroline, and stimulation of their activity by $\mathrm{Ca}^{2+}$. Based on previous reports (Metayer et al. 2002; Shimokawa et al. 2002; McCauley et al. 2001; Tentes et al. 2007), the bands with 225, 78 and $66 \mathrm{kDa}$ correspond to dimer-MMP-9, proMMP-2 and active MMP-2. The variation in molecular weights (by 10 to $15 \mathrm{kDa}$ ) of gelatinases of different origins can be result of different glycosylation (Metayer et al. 2002). Bands with lower molecular weights can represent the degradation products of metalloproteases with enzymatically active domain (Shimokawa et al. 2002). This can be explained because both MMP-2 and MMP-9 have gelatin binding domains in their catalytic domains (Banyai et al. 1994).

Higher values of semen indicators correlate with lower concentrations of metalloproteases in seminal plasma. Similarly, in human seminal plasma a higher concentration of pro-MMP-9 was detected in semen with abnormally low sperm concentration (Tentes et al. 2007). The same study reported that inactive or active forms of MMP-2 and MMP-9 do not correlate with semen indicators. Our results indicate that higher concentrations of metalloproteases of 78, 66 and $225 \mathrm{kDa}$, that correspond to active MMP-2, pro-MMP-2 and dimer MMP9 , correlate with higher concentrations of acrosome damage. In human sperm samples, MMP-2 and MMP-9 were detected by immunofluorescence in the acrosome region and midpiece (Buchman-Shaked et al. 2002). In the case of abnormal sperms, MMP-9 was also found in the acrosome region (Buchman-Shaked et al. 2002). Since the acrosome is important for the penetration of the oocyte, its integrity is vital for optimal fertilising capacity. In spermatozoa, different proteases are mainly localized within the acrosomal vesicle (Tulsiani et al. 1998). All measured semen indicators were significantly lower in a group with SI $<$ than in a group with SI above $110 \mathrm{M} / \mathrm{ml}$. A negative correlation was observed between metalloproteases (proposed active MMP-2 and pro-MMP-2) and sperm concentration, as well as motility. A higher degree of acrosome damage was observed in a group of semen with $\mathrm{SI}<110 \mathrm{M} / \mathrm{ml}$, with significantly higher concentrations of proposed MMP-2 and pro-MMP-2. The acrosome reaction, namely the release of enzymes to penetrate the zona pellucida, should take place at the place of fertilization (Woelders 1991). Keeping these sperm proteases in an inactive form is crucial for maintaining cell integrity to ensure good reproductive function (Uhrin et al. 2000). Therefore, our results suggest that a higher concentration of 66 and $78 \mathrm{kDa}$ metalloproteases (proposed as MMP2 and pro MMP-2) is the result of acrosome damage. On the other hand, no correlation was observed between sperm characteristics and enzyme activity of gelatinases without metalloprotease activity.

Our results demonstrate that metalloprotease activities correlate with sperm index, which combines sperm concentration, motility and morphology and therefore provides a better evaluating of semen quality than assessing the characteristics mentioned above independently. Therefore, the examination of metalloproteases in seminal plasma by the method used here could be a valuable tool for semen evaluation. Further studies will be focused on the function of metalloproteases in the process of capacitation and maturation of boar spermatozoa.

\section{Acknowledgements}

This work was supported by the Slovenian Research Agency, programme group "Endocrine, immune, nervous and enzyme responses in healthy and sick animals" (P4-0053). Authors thank Petra Domanjko and Mojca Kavčnik DVM for help with semen evaluation and Prof. Roger Pain for critical reading of the manuscript.

\section{References}

Banyai L, Tordai H, Patthy L 1994: The gelatine-binding site of human $72 \mathrm{kDa}$ type IV collagenase (gelatinase). Biochem J 298: 403-407 
Baumgart E, Lenk V, Loening SA, Jung K 2002: Tissue inhibitors of metalloproteinases 1 and 2 in human seminal plasma and their association with spermatozoa. Int J Androl 25: 369-371

Birkedal-Hansen H, Taylor RE 1982: Detergent-activation of latent collagenase and resolution of its component molecules. Biochem Biophys Res Commun 107: 1173-1178

Buchman-Shaked O, Kraiem Z, Gonen Y, Goldman S 2002: Presence of matrix metalloproteinases and tissue inhibitor of matrix metalloproteinase in human sperm. J Androl 23: 702-708

Hafez ESE 1993: Semen evaluation. In: Hafez ESE (Ed.) Reprod in Farm Animals (6 ${ }^{\text {th }}$ ed.). Philadelphia, PA, pp. 405-423

Hulboy DL, Rudolph LA, Matrisian LM 1997: Matrix metalloproteinases as mediators of reproductive function. Mol Hum Reprod 3: 27-45

Kotlowska M, Kowalski R, Glogowski J, Jankowski J, Ciereszko A 2005: Gelatinases and serine proteinase inhibitors of seminal plasma and the reproductive tract of turkey (Meleagris gallopavo). Theriogenology $\mathbf{6 3}$ : 1667-1681

Laemmli UK 1970: Cleavage of structural proteins during assembly of the head of bacteriophage T4. Nature 227: 680-685

Mahmoud AM, Comhaire FH, Vermeulen L, Andreou E 1994: Comparison of the resazurin test, adenosine triphosphate in semen, and various sperm parameters. Hum Reprod 9: 1688-1693

McCauley TC, Zhang HM, Bellin ME 2001: Identification of a heparin-binding protein in bovine seminal fluid as tissue inhibitor of metalloproteinases-2. Mol Reprod Develop 58: 336-341

Metayer S, Dacheux F, Dacheux JL, Gatti JL 2002: Comparison, characterization and identification of protease inhibitors in epididymal fluids of domestic mammals. Matrix metaloproteinases are major fluid gelatinases. Biol Reprod 66: 1219-1229

Nagase H, Woessner JR JF1999: Matrix metallo-proteinases. J Biol Chem 274: 21491-21499

Robinson LL, Sznajder NA, Riley SC, Anderson RA 2001: Matrix metalloproteinases and tissue inhibitors of metalloproteinases in human fetal testis and ovary. Mol Hum Reprod 7: 641-648

Shimokawa K, Katayama M, Matsuda Y, Takahashi H, Hara I, Sato H 2003: Complexes of gelatinases and tissue inhibitor of metalloproteinases in human seminal plasma. J Androl 24: 73-77

Shimokawa K, Katayama M, Matsuda Y, Takahashi H, Hara I, Sato H, Kaneko S 2002: Matrix metalloproteinase (MMP)-2 and MMP-9 activites in human seminal plasma. Mol Hum Reprod 8: 32-36

Tentes I, Asimakopoulos B, Mourvati E, Diedrich K, Al-Hasani S, Nikolettos N 2007: Matrix metalloproteinase (MMP)-2 and MMP-9 in seminal plasma. J Assist Reprod Gen 24: 278-281

Tulsiani DRP, Abou-Haila A, Loeser CR, Pereira BMJ 1998: The biological and functional significance of the sperm acrosome and acrosomal enzymes in mammalian fertilization. Exp Cell Res 240: 151-164

Uhrin P, Dewerchin M, Hilpert M, Chrenek P, Schöfer C, Zechmeister-Machhart M, Krönke G, Vales A, Carmeliet P, Binder BR, Geiger M. 2000 Disruption of the protein C inhibitor gene results in impaired spermatogenesis and male infertility. J Clinic Invest 106: 1531-1539

Woelders H 1991: Overview of in vitro methods for evaluation of semen quality. International Conference in Boar Semen Preservation, pp. 145-165

Zheng X, Geiger M, Ecke S, Bielek E, Donner P, Eberspächer U, Schleuning WD, Binder BR.1994: Inhibition of acrosin by protein $\mathrm{C}$ inhibitor and localization of protein $\mathrm{C}$ inhibitor to spermatozoa. Am J Phys 267: C466-C472

Zrimšek P, Kunc J, Kosec M, Mrkun J 2004: Spectrophotometric application of resazurin reduction assay to evaluate boar semen quality. Inter J Androl 27: 57-62

Zrimšek P, Kunc J, Kosec M, Mrkun J 2006: Determination of the diagnostic value of the resazurin reduction assay for evaluating boar semen by receiver operating characteristic analysis. Asian J Androl 8: 343-348 
Plate IV

Zakošek Pipan M. et al.: Gelatinases in ... pp. 491-496

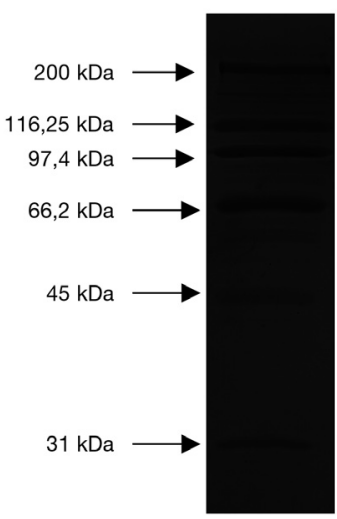

Standard

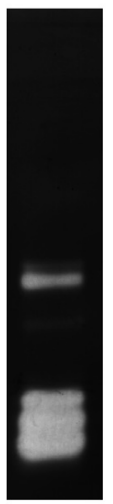

A

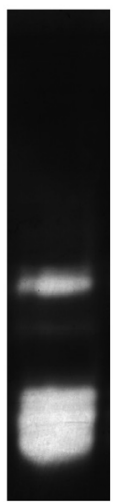

B

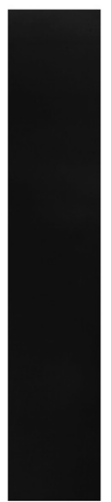

C

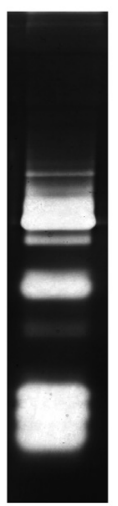

$\longleftarrow 225 \mathrm{kDa}$

$48 \mathrm{kDa}$

$-66 \mathrm{kDa}$

$64 \mathrm{kDa}$

$59 \mathrm{kDa}$

$45 \mathrm{kDa}$

$40 \mathrm{kDa}$

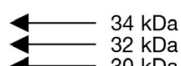

D

Fig. 1. The presence of gelatinases in boar seminal plasma

Molecular weight of standards is shown on the left. Lanes A, B and C correspond to the gelatinolytic band patterns obtained after reactivation of the enzyme activity without $\mathrm{CaCl}_{2}$, in the presence of EDTA and in the presence of phenanthroline, respectively. Lane D represents different forms of gelatinases with their molecular weight (arrows). 